in the case of B. vs. C. in 1877, didn't I? You say I am in sane. Can you point out any case of insanity sinilar to mine, and can you really tell whether I have paretic mania, or circular insanity, or a sore throat, or corns? You doctors are anusing cusses. You bury your mistakes, while tbose of us Tawyers are filed for record.

The witness replied:

I'm sure you are insane, Mr. X., but I can not classify your case. It's constitutional insanity.

A verdict of insanity was now rendered, but two philanthropists who had become interested in X.'s case and , thought they could care for and benefit him, interceded with the court to be given charge of him, and were al* lowed by the court to assume this responsibility. The sequel to the efforts of these benevolent gentlemen was what might have been expected. Within two or three days $X$. was again in the county jail and applied again for a writ of habeas corpus, but was refused by several judges in succession. He was now compelled to returm to the Detention Hospital to await his transfer to some institution for the insane. It was for several weeks, however, found impossible to secure his admission to any public or private asylum, though anplication was made to a large number. It became impossible on account of his violence longer to care for him properly in - the Detention Hospital and he was transforred to the county jail and finally to the Cook County Asylum for - the Insane at Dunning, and was there during some months in a maniacal state. He gradually improved and was allowed to go about with an attendant on the country roads, where he amused himself by plaving Robin Hood and "holding up" every person he met with a demand for cigars, money or plunder of any sort.

\section{NORMAL INTERVAL.}

He now gradually became more rational and quiet and was finally released "on probation" October 21. During the winter of 1891-1892 X. was again in a depressed and inactive state, again approximating his natural condition in the early spring, and passing through a customary normal interval.

This was followed by a gradual return of the maniacal cycle.

\section{FOURTH MANIC-DEPRESSIVE CYCLIE.}

During the summer of 1892 a succession of his customary pranks and depredations attracted public attention, furnishing amusement or annovance, as the case might be. He was arrested for disorderly conduct and

- for disturbing the peace, and appeared in absurd or equivocal situations and adventures in towns and cities of Illinois and surrounding states, especially gaining notoriety by his exploits at the National Republican Convention at St. Paul: In the summer or fall of this year $X$. was again committed to the Cook County Asylum for Insane,

y passing through the usual maniacal exacerbation. When his condition had become more quiet he one day made his escape with the assistance of a woman who drove through the grounds and took him into her carriage. This escape was planned by assistance of outside persons and a disguise furnished $X$. consisting of a wonian's clothing. The winter of 1892 and $\mathbf{1 8 9 3}$ appears to have been uneventful, and apparently in the spring of 1893 the usual "March madness" did not occur. X. went to Colorado in the summer of 1893 and made special effort to control himself with a view to regaining control of his property, which was still in the hands of a conservator. He was at this time more milly mani- acal, though, while stopping at Colorado Springs, he attracted much attention and at times people avoided the Pike's Peak cog-wheel railroad trains when he was aboard and the hotels and public places where he disported himself. From this time there was greater irregularity in the cycles and the normal intervals were less marked. At the meeting of the American Medico-Psychological Association in Chicago in June, 1893, he attended one of the sessions and requested to be allowed to addrass the association, and whilc sitting in the meeting fell asleep in his chair. He had grown very gross and corpulent. There appears to have been from this time a more decided moral and mental deterioration. Though he still at times was brilliant and able to carry on spasmodically a law business consisting largely of habeas corpus proceedings and attempts to release patients in asylums, he never equaled his former achievements, and evidence of degeneration was shown in many acts, foreign to his normal self, of an indecent or quasi-criminal character.

(To be continued.)

\section{A CASE OF PARASITIC HEMOPTYSIS OR IN- FECTION WITH THE DISTOMA WESTERMANII.}

A. D. MACKENZIE', M.D.

Attending Physician to St. Vincent's Hospital. PORTLAND, OREGON.

The value of the examination of sputum for tubercie bacilli depends almost solely on their presence, and it is generally recognized that repeated failure to fird them does not exclude the existence of tuberculosis in the lungs.

This fact is intimately connected in its relation to differential diagnosis, with the characteristics of the sputum in parasitic hemoptysis, for in this disease some of the general symptoms of tuberculosis, such as emaciation, general weakness and anemia, are usually associated with the continued expectoration of blood$s$ ained, mucopurulent material. There are obvious reasons, especially applicable to certain parts of the United States, why parasitic hemoptysis should be excluded in cuses suspected of being tuberculous, and in which the sputum is free from tubercle bacilli, although it continuously possesses various admixtures with blood.

This is illustrated by the following account of a case admitted to my service in the St. Vinc nt's Hospital of Portland, Oreg. It is, so far as I am aware, the first instance of parasitic hemoptysis observed on this continent.

History.-A Japanese man, a native of the province of Okayama, was admitted Nov. 23, 1903, suffering from weakness and persistent hemoptysis. He arrived on this continent the preceding April and had been employed by the fish canneries of Vancouver and Victoria during the summer.

His first attack of hemoptysis occurred July 17, 1903, while rowing a boat against a strong tide in the Columbia river; four or five ounces of blood, described as bright red, escaped by coughing. A cough with blood-stained expecioration continued after this attack, with slight intermissions, until he applied for admission to the hospital. Friends accompanied him to the hospital, desiring assurance that he did not have tuberculosis.

Ixamination.-At the time or admission he had lost some weight and complained of slight transient pains in both sides of the chest, in front and behind, and varying from day to day in location. On examination cogwheel respirations and a hemic murmur were found the chest was well developed. Although the chest was carefully examined at different times dur- 
ing his stay at the hospital, both by myself and by other members of the attending staff, the few alterations mentioned were not supplemented.

IJuring his stay in the hospital blood was always found in the sputum; for a time it resembled pneumonic sputum, later a mieroseopic examination was necessary to find the blood. At times there were found little yellow particles in the sputum like plugs of bronchioles; they were frequently tipped at one end with clotted blood. Repeated examinations of the sputum were made for the tubercle bacilli with uniformly negative results. There were no accounts of tuberculosis in the family history and he had never been sick before; with exception of gonorrhea several years before, from which recovery was prompt.

The ova of the distoma were finally found in the sputum and their nature confirmed by Dr. C. W. Stiles of the U. S. Bureau of Animal Industry; charcot-Ieyden crystals were also abundant.

He had no temperature, ate and slept well and gradually so recovered that longer retention in the hospital was impossible. The hemoglobin was 70 per cent. (Tallqvist) and examination of the corpuscles of the blood revealed no noteworthy alterations in number or character.

'There are recorded three instances in which observations have been made in this country of pulmonary infection in animals with parasites of this variety, the first by Ward $^{1}$ in a cat, the second by Kellicott and Ward in a dog, the third by Payne and other members of the Bureau of Animal Industry in hogs. These observations have formed the basis of a number of publications, of which those by Ward, and by Stiles and Hassall, deserve special mention. The infection in hogs was observed in Cincinnati where, for a period in 1898, 1 per cerit. of the animals inspected were found infected. The flukes found in the cat concerned an animal of Ann Arbor; those in the dog were found in Columbus, Ohio.

In other countries, other observers, including Kerbert, who named the parasite after Westerman, have found it in the lungs of the tiger. In Japan, dogs and cats both serve as final hosts. Although there are differences noted in the descriptions of this trematode, as it occurs in man and animals, the reasons for considering that separate species have been described are as yet insufficient. Likewise the Asiatic and American forms are believed to be identical, although, as stated by Stiles, a zoologic error may be made, in so doing, in the interests of hygiene.

There is every reason to believe the infection in the case here reported was contracted in Japan. The disease is endemic in the province Okayama from which he came; in fact, it was to this province that Yamagiwa and Inoui were sent by the Japanese government in 1890 to study the disease.

Most of the writings concerning the disease have been by the Japanese, and unfortunately they are, to a large degree, in that language. Two of the articles by Yamagiwa, ${ }^{2}$ one by Katsurada, ${ }^{3}$ and the recent one by Taniguchi, ${ }^{4}$ however, are in Grrman, and contain references to the accounts of many of their countrymen.

As at present understood, the Distoma or Paragonimus westermanii is responsible for two widely different forms of disease in man-the pulmonary and the cerebral. In both, cysts are likely to be found as the chief anat-

1. For bibliography see Notes on Parasites 51.-The Lung Fluke (Paragonimus Westermanii) in Swine, and Its Relation to Parasitic Hemoptysis in Man. Sirteenth Annual Report, Bureau of Animal Industry. U. S. Dept. of Agriculture, 1899, 560, by Charles Wardelt Stiles and Albert Hassall.

2. Firchow's Archiv, 1890, exix, 447, and 1892. cxxril, 446.

3. Ziegler's Beitrage, 1900, xxviii, 506.

4. Arch. f. Psychiatrie u. Nervenkrankheiten, 1904, xxxviii, 100. omic change. Those in the lungs are usually in the upper lobes and near the surface where they may form brownish or darker projections. Their shape is described as flat (Yamagiwa) or round (Katsurada), and their size about that of the tip of the little finger.. When they contain parasites there is also a viscid brownish-gray fluid, and the lining is rough, ragged or wrinkled. They rarely contain more than a single worm in man. Their firm walls measure a millimeter in thickness, and are formed solely by the tissues of the host.

Participation of the bronchi and bronchioles in the. formation of such cysts by dilatation was demonstrated by Katsurada in dogs and cats, but not in human lungs, although these channels always lead into the cysts. In the lungs so infected a bronchitis occurs with a mucopurulent and hemorrhagic exudation, as well as various forms of pneumonia, depending on the stage of the infection and on repeated infection. The nodules form- 1 ing about the ova are said to simulate chalicosis, and in one case (Case 1 of Katsurada's article ${ }^{3}$ ) the lung was very cirrhotic from the disease; bronchiectasis and emphysema may be consecutive changes. Nodules inclosing ova and resembling tubercles may occur in the pleura."

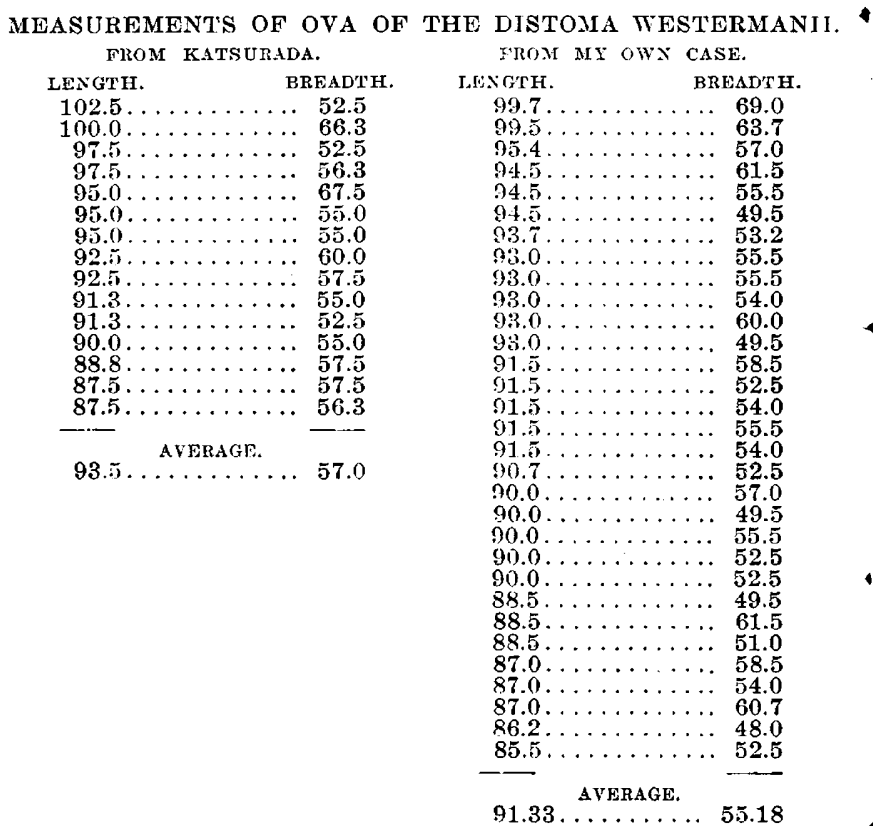

Considerable interest is connected with the origin of cysts in the brain on account of the degree to which the softening following embolism is responsible for their formation. They are described as varying in size from a grain of rice to a pigeon's egg, or larger, and communicating. ${ }^{6}$ In one case no cavities occurred, but instead dark fibrous nodules inclosing ova. ${ }^{2}$

In the cerebral cysts, or more correctly, pseudocysts, both adult worms and ova have been found. In 11 cases of parasitic hemoptysis, in which Inoui observed cerebral symptoms, there were six in which the unilateral spasms were in some cases accompanied by paresis, two with general epilepsy, two with hemiplegia and one with psychic blindness. ${ }^{4}$ In the case reported by Taniguchi, in addition to the usual symp-

5. In Miura's description of such nodules in 1899 (Virchow's Archiv, cxvi, 310), the ova are mentloned as being those of the common liver fluke; this has been corrected by subsequent writers. 6. I have been inable to find any account in Miura's article, of the cerebral infection referred to by Stiles and Hassall. 
toms of epilepsy, those of athetosis and chorea were present. His anatomic study of the brain lesions led him to believe the walls of the cysts were, in part, formed by the vessels by which embolism occurred.

In other parts of the body either the ova or worms have been found in the liver, orbital cavity, lower eyelids, scrotum, mesentery, diaphragm, omentum and in the contents of the intestine.

Thirty-one of the ova were measured by Dr. E. R. LeCount of Rush Medical College, Chicago, care being - taken to select such as were yet unbroken. ${ }^{7}$ The sizes (see accompanying table) were found to correspond fairly well with the measurements given by most authorities, particularly those of Katsurada.

\section{ILLEGITIMACY AN ECONOMIC PROBLEM.}

JAMES E. DAVIS, M.D., PH.G.

Obstetrician to Mercy Hospital and to Salvation Army Rescue Home. DETROIT.

"To such grievances as society can not readily cure, it usually forbids utterance on pain of its scorn; this scorn being only a sort of tinseled cloak to its deformed weakness."Currer Bell, quoted by Shirley.

"The duty of Christian society is to find its work and to do it."-Carlyle.

"Society is organic; that is to say, it is like an organ- ism, in that it is composed of interdependent parts performing functions essential to the life of the whole."1 The conservation of the race when economically considered, begins with the personal unit, which has both known and unknown values. The unknown unit, plus environment and heredity, represents a known quantity, which becomes a factor in the product of society. En- vironment and heredity are always subject to the qualifications of "accidentals,". which may be either voluntary or involuntary.

"Clear knowledge. is confused when we can not distinguish the parts and qualities of the thing known, and can only recognize it as a whole." Thus it follows that it is the "accidentals" which are the confusing factors in our political science. "The life of society may be conveniently divided into eight parts, called life-spheres, viz.: (1) language, (2) art, (3) science and education, (4) family life, (5) social life in the narrower sense, that is, the intercourse of friends and associates; (6) religious life, ( 7 ) political life, (8) economic life."2

The problem of illegitimacy has a vital position in six of the eight spheres. The personal unit may or may not be privileged a volitional environment; a specific example of the first would be that of the child which chooses a new home with foster parents and a changed society life before his sexual education begins. The resultant changes will be commensurate with the fixation processes of the environment, and the contrast of the two possibilities will be less or greater as the heredity is paralleled or opposed. Add to this the compliment of accidentals, which is subject to the same law as heredity.

The example of denied volitional environment will, as a rule, trend toward'a phase of life having the least resistance, which has, in most instances, been made by heredity. The possibility of accidentals that paralle] the hereditary taints is greatly increased.

7. The stage micrometer employed (Bezu, Hausser et Cie, Paris) contains 100 lines to one-fifth of a millimeter.

* Read before the Wayne County Medical Society, Detroit.

1. Ely : Political Economy, pp. 5-6.

2. Leibnitz: Jevons' Lessons in Logic, p. 55.
Heredity may be either primary or secondary to environment. If primary, then it follows that the heredity had its beginning in the class of accidentals. To exemplify, it is sufficient to instance the accidentals which occur in a line without taintured chastity when amatory passion is causative of procreation out of wedlock.

The certainty of heredity in its primary form, causing an environment for the succeeding generation, is well established, and "it is a general biologic law that the lower the position of an animal in the scale of being, the greater its capacity for the reproduction of its kind." "Hereditary tainture existing in an environment of its kind, is procreated through succeeding generations in the case of bastardy to an astonishing degree," as is graphically shown in the tables of Spitzga and of Dugdale. ${ }^{5}$

The term "accidentals" is here used advisedly and for convenience, there being no English word to distinguish-in contrast to the woman who professionally sells herself-the one who lapses through imprudence, ignorance or passion, and afterward recovers and leads a reputable life. 'To this class is assigned all women of good heredity, good environment and heretofore unquestioned chastity, who yielded to temptation from causes that were immediate and seemingly insuperable.

Illegitimacy in its generic sense is an inadequate term, referring specifically to the state of being born out of lawful wedlock. In this paper the term is used to designate a vice, in which is the implication of a child, a mother, a father, the relatives, friends and community. It is the purpose of social economics to apply principles to problems connected with the growth and wellbeing of organized society.

It is the intent of this study to submit statistics and other material which can be used for inductive and deductive reasoning toward the formulation of applied principles for a subject which can be said to have substantially a very meager literature and comparatively few investigators. The difficulties that confront the student of illegitimacy are evident to all who have given the subject but little attention.

The general rules ${ }^{6}$ of method in composing any discourse require, first, that nothing should be wanting or redundant; second, that the separate parts should agree with each other; third, that nothing should be treated unless, it is suitable to the subject or purpose; fourth, that the separate parts should be connected by suitable transitions.

It is impossible to exclude the evidence of statistics in a scientific study of illegitimacy, and it is impossible to include them for all geographical divisions. There are in the United States 53 states and territories (including the Hawaiian Islands and Alaska). Of this number, 39 have state boards of health. Letters of inquiry for statistjes relative to illegitimate births were sent to every secretary. Repljes were received from 25 of the $39 ; 19$ replied that there were ro statistics taken. Many do not have any record of births, while some do not keep evcn death records.

Six states-Connecticut, Minnesota, Rhode Island, North Dakota, Indiana and Michigan-have records. In every instance the figures were affirmed by the secretaries to be unreliable, therefore of little value excepting

\footnotetext{
3. McKlm: Heredity and Human Progress, p. 120.

4. Spitzga: The Iegal Disabilities of the Natural Child, Alienist and Neurologist, October, 1899.

5. Dugdale: 'Table 5, The Jukes, p. 27.

6. Jevons' Logic, p. 202.
} 